\title{
Percepção da culinária regional em festa popular no semiárido da Paraíba, Brasil
}

\section{Cristiane Bezerra Libório Correia ${ }^{1}$,*, Vitor Hugo Rocha de Vasconcelos $^{1}$, Valeria Louise de Araújo Maranhão Saturnino Silva ${ }^{1}$, Reinaldo Farias Paiva de Lucena $^{2}$ e Flávia de Oliveira Paulino ${ }^{3}$}

\footnotetext{
${ }^{1}$ Universidade Federal da Paraíba. Unidade Mangabeira. Centro de Tecnologia de Desenvolvimento Regional. Departamento de Gastronomia. Campus I. Rua dos Escoteiros, S/№. Mangabeira. João Pessoa-PB, Brasil (CEP 58058-660). *E-mail: cristiliborio@gmail.com.

${ }^{2}$ Universidade Federal da Paraíba. Centro de Ciências Exatas e da Natureza. Departamento de Sistemática e Ecologia. Programa de Pós-Graduação em Desenvolvimento e Meio Ambiente. Campus I. João Pessoa-PB, Brasil (CEP 58051-900).

${ }^{3}$ Universidade Federal da Paraíba. Centro de Biotecnologia. Departamento de Biotecnologia. Programa de Pós-Graduação em Desenvolvimento e Meio Ambiente. Campus I. João Pessoa-PB, Brasil (CEP 58051-900).
}

Resumo. A Festa do Bode Rei é um importante festival popular no Estado da Paraíba. A culinária regional desempenha um relevante papel no festival, cujo principal elemento é o caprino. 0 estudo objetivou investigar se os alimentos comercializados no festival promovem o desenvolvimento social e a recuperação dos costumes regionais, e se espécies nativas da Caatinga são utilizadas na culinária. Para isso foram aplicados dois inquéritos, aos comerciantes e ao público. Os resultados mostraram que o público é formado principalmente por turistas e que a comida é uma das razões mais relevantes para a participação, que expressam a culinária típica e utilizam ingredientes locais. No entanto, as espécies nativas não foram utilizadas. Verificou-se que a maioria das pessoas prefere barracas a estabelecimentos fixos e que estes não são operados por vendedores locais. Concluiu-se que o evento é importante para ajudar o desenvolvimento e fazer transmissão cultural.

Palavras-chave: Comida; Cultura; Festividade; Nordeste, brasileiro.

Abstract. Perception of regional cuisine at a popular party in the semi-arid region of Paraíba, Brazil. The Bode Rei festivity is an important popular festival in the Paraiba State. The regional cuisine plays a relevant role in the festival, whose main element is the goat. The objective study is to investigate if the foods marketed in festival has promoted the social development and the recovery of regional customs, if native Caatinga species has

Recebido

$16 / 02 / 2020$

Aceito

$21 / 04 / 2020$

Disponível on line

$22 / 04 / 2020$

Publicado

$30 / 04 / 2020$

Acesso aberto

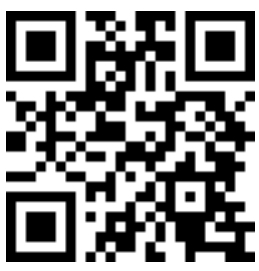

ISSN 2359-1412/RBGAS-2020-0028/2020/7/15/11/139

Rev. Bras. Gest. Amb. Sustent.

http://revista.ecogestaobrasil.net 
been used in culinary. For this, two surveys were applied, to the merchants and the public. The results showed the public is mainly made up by tourists and that the food is one of most relevant reason to participation, which express the typical culinary and utilize local ingredients. However, the native species haven't been used. It was verified most people prefers tents to fixed establishments and that tents aren't operated by local vendors. Finally, the event is important to help development and cultural transmission.

Keywords: Food; Culture; Festivity; Northeast Brazilian.

Resumen. Percepción de la cocina regional en una fiesta popular en la región semiárida de Paraíba, Brasil. La Festa do Bode Rei es una important fiesta popular en el Estado de Paraíba. La culinaria regional desempeña papel pertinente en festival, cuyo elemento principal es el caprino. El objetivo fue investigar si los alimentos comercializados en festival han fomentado el desarrollo social y la recuperación de las costumbres regionales, si se ha utilizado especie nativa Caatinga en la culinaria. Se han aplicado dos encuestas, a los comerciantes y al público. Los resultados mostraron que el público está formado principalmente por turistas y que la comida es una de las razones más relevantes para la participación, que expresan la típica culinaria y utilizan ingredientes locales. Pero, las especies nativas no han sido usadas. Se verificó que la mayoría de la gente prefiere cabinas a establecimientos fijos, y que estos no son operadas por vendedores locales. Finalmente, el evento es importante para ayudar al desarrollo y hacer la transmisión cultural.

Palabras clave: Comida; Cultura; Fiesta; Nordeste brasileño.

\author{
(1) 0000-0001-6431-9924 \\ Cristiane Bezerra \\ Libório Correia \\ (D) 0000-0001-6988-5001 \\ Vitor Hugo Rocha de \\ Vasconcelos \\ D 0000-0001-7546-078X \\ Valeria Louise de \\ Araújo Maranhão \\ Saturnino Silva \\ () 0000-0003-4775-7775 \\ Reinaldo Farias Paiva \\ de Lucena \\ D 0000-0001-6377-3594 \\ Flávia de Oliveira \\ Paulino
}

\section{Introdução}

Cultura é definida como os costumes de um povo, transmitidos por interações naturais e históricas, de geração em geração, garantindo a identidade dos mesmos além de orientar para onde uma população seguirá. Ela tem como base de sua formação a sociedade, política e economia, uma depende da outra de maneira indissociável. A cultura popular envolve vários setores como pesquisa, artesanato, agricultura, pecuária, lazer, alimentação, sendo utilizada como proposta de desenvolvimento regional. Quando isso ocorre de forma sustentável não movimenta apenas a economia, mas também eleva a qualidade de vida da população local, pois promove um reencontro com a identidade regional pela valorização do território e dos seus produtos (Lóssio e Pereira, 2007; Godoi, 2008; Brito et al., 2012; Reis, 2013; Martins, 2014).

Uma forma de divulgação do lugar e da cultura são as festas populares, nas quais ocorre uma movimentação econômica por meio do resgate de valores e da preservação cultural. Esse tipo de festa pode ser bastante benéfico pois permite difusão de saberes, interação com o meio e não causa significativos impactos ambientais, culturais e no cotidiano da região. Esses impactos sociais e culturais não são significativos uma vez que a mudança de rotina da comunidade ocorre apenas durante o festejo, podendo a comunidade continuar com suas atividades rotineiras nos demais períodos (Pereira, 2006; Caponero e Leite, 2010). 
Uma das festas populares mais famosas do semiárido do Nordeste do Brasil é a Festa do Bode Rei, que ocorre no município de Cabaceiras, localizada na mesorregião da Borborema, no estado da Paraíba. Essa festa destacou-se ao longo dos anos e tornou-se tão importante quanto outros festejos tradicionais do Estado, atraindo uma média de público de 60 mil pessoas e, gerando em torno de 850 empregos diretos e indiretos (Duarte, 2016; Costa, 2017).

Tal sucesso ocorreu devido a ações mercadológicas e culturais, visto que $25 \%$ da população local exerce atividades na caprinocultura. Para a região o festejo é relevante pois proporciona movimentação econômica tendo em vista que o índice pluviométrico da mesma é um dos menores do país, o que restringe as possibilidades de cultivo e de criação animal. Dessa forma, umas das possibilidades de movimentação econômica são o turismo rural (Lajedo de Pai Mateus e Saca de Lã) e os eventos. A Festa do Bode Rei é repleta de atrações que possuem como sua figura principal o bode. Dentre as atividades que ocorrem na festa pode-se destacar a escolha da rainha da festa, a competição da cabra leiteira, a fórmula bode e o pega bode (Pinheiro, 2003; Alves et al., 2008; Papes e Sousa, 2011; Duarte, 2016).

Um ponto que se faz importante no contexto das festas populares é a culinária regional. Esse tipo de culinária é o reflexo da alimentação da população, podendo alguns componentes estar mais presentes na forma cotidiana e outros, mais em atividades festivas. A comida conhecida com típica da região nordeste brasileira tem como base o boi (carne seca e carne de sol), o carneiro e o bode, a macaxeira, o milho e o jerimum. Dentre as frutas, destacam-se o abacaxi, o caju, a goiaba, o sapoti, o cajá, entre outras. Diferenciar as cozinhas de Pernambuco, Alagoas e Paraíba é um desafio, uma vez que é comum que nesses três estados brasileiros a culinária seja dividida em "comida sertaneja" e "comida litorânea". No interior da Paraíba, alvo desta pesquisa, a comida sertaneja é fortemente marcada pela rusticidade, incluindo alimentos como rapadura, rubacão, farinha de mandioca, bode, e cachaça (aguardente de cana-de-açúcar) como bebida (Godoi, 2008; Campos et al., 2009; Mendes et al., 2014).

0 modo como os alimentos são consumidos e comercializados também refletem a cultura local. Dentro os modos de preparação e comercialização de alimentos têm-se a informalidade, fora de uma estrutura física fixa, ela é caracterizada por se de rápido preparo, baixo custo e de qualidade higiênico-sanitário duvidosa. Essa última característica pode ocorrer tanto pela falta de estrutura adequada quanto pelo manipulador que nem sempre tem formação ou instrução adequada para tal atividade, tornando-se um contaminador em potencial dos alimentos que, consequentemente, podem transmitir doenças aos consumidores (Aluko et al., 2014; Rodrigues, 2014; Silva et al., 2014; Cortese et al., 2016).

A respeito da estrutura física, quando a mesma é precária afeta toda a cadeia produtiva, desde o preparo até o armazenamento, além de oferecer condições aos consumidores condições mínimas para realização da higienização das mãos, permitindo que o mesmo se auto contamine. A consequência dessa contaminação é a toxinfecção alimentar que pode ser mais de 200 tipos diferentes de enfermidades de origem viral, parasitária ou bacteriana (Okojie e Isah, 2014; Qureshi et al., 2015).

Neste contexto da alimentação, a Festa do Bode Rei tem como principal personagem o animal conhecido como referência da resistência à seca e de sustento econômico da região. 0 caprino adapta-se a longos períodos secos e ainda fornece a carne, o leite e o couro. No nordeste brasileiro, a criação deste animal iniciou-se na época da colonização e permanece ainda nos dias atuais exercendo grande importância no cenário agropecuário, representando quase $90 \%$ do rebanho nacional da ovinocaprinocultura. Além das questões históricas, a caatinga, vegetação nativa da região, tem elevado valor nutricional para esse animal, principalmente em grandes períodos de seca, o que torna a região favorável ao manejo da caprinocultura (Pinheiro, 2003; Costa, 2008; Pereira e 
Souza, 2013; Nunes et al., 2014; Batista e Souza, 2015; Ribeiro et al., 2015; Aquino et al., 2016; Duarte, 2016; Silva et al., 2016).

O objetivo geral desta pesquisa foi verificar se a Festa do Bode Rei no município de Cabaceiras, na Paraíba, está sendo um fator de desenvolvimento social e valorização da cultura local através da culinária e da utilização das espécies nativas da Caatinga. Objetivou-se também analisar a origem e o comportamento do frequentador da festa, suas motivações e o tipo de consumo que faz no local, especialmente em relação à culinária.

\section{Metodologia}

\section{Área de estudo}

Cabaceiras é um município do estado da Paraíba, situado na região do semiárido do Nordeste brasileiro, distante aproximadamente a $180 \mathrm{Km}$ da capital do Estado, com $300 \mathrm{~m}$ do nível do mar, localizado na região geográfica do Baixo Planalto da Borborema. Apresenta os menores índices pluviométricos do país, o que restringe as possibilidades agropecuárias. Outra possibilidade de movimentação econômica é o turismo ecológico e os eventos festivos realizados na região. Dentre elas, tem-se a festa do Bode Rei. Um dos seus destaques é a comercialização de caprinos e ovinos, além do turismo rural e atividades de entretenimento com shows, competições e a venda de alimentos típicos a base de bode (Papes e Sousa, 2011; Duarte, 2016; Costa, 2017).

\section{Coleta dos dados}

Em relação aos métodos, a pesquisa foi realizada a partir de duas técnicas, uma conhecida por bola de neve ou "snowball sampling" (Biernacki e Waldorf, 1981), e outra através da abordagem aleatória de entrevistados (Lakatos e Marconi, 2002), apresentando assim uma abordagem quali-quantitativa.

Para a realização da pesquisa foram adotadas duas técnicas: Para a aplicação de questionários nos estabelecimentos comerciais, que trabalham com alimentos prontos para consumo do Município de Cabaceiras, foi utilizada a técnica de bola de neve. Ela consiste em visitar um primeiro estabelecimento e a partir dele outro, mediante indicação do visitado e assim sucessivamente, até se esgotar todos os estabelecimentos.

Já na entrevista dos participantes da festa, a técnica escolhida utilizada foi a abordagem aleatória. Para sua realização foram abordados os atores de forma aleatória nas proximidades dos polos onde ocorria o festejo como praças e ruas da cidade. Os entrevistados participavam da pesquisa, mediante consentimento do mesmo, respondendo um formulário semi-estruturado que foi utilizado como instrumento de pesquisa.

Depois de definidas as técnicas a serem utilizadas a pesquisa foi dividida em duas etapas: visita aos estabelecimentos comerciais; e entrevistas nas praças e ruas da cidade. Durante a primeira etapa foram visitados 21 estabelecimentos, sendo 13 barracas temporárias e oito restaurantes e/ou lanchonetes fixos na cidade. Os responsáveis diretos dos respectivos estabelecimentos foram os escolhidos para responder os formulários. As questões indagadas foram contextualizadas no seguinte viés: tipos de alimentos mais comercializados durante a festa, origem dos ingredientes utilizados para a confecção dos mesmos, se os suprimentos usados nos pratos são nativos ou exóticos, dentre outros.

A segunda parte da pesquisa ocorreu por meio das entrevistas com os participantes da festa. Dentre esses agentes sociais existia a população local, que reside na própria cidade, e a população externa, que reside em outros municípios, dentro ou fora do estado da Paraíba. A partir desta distinção os entrevistados foram divididos entre pessoas habituadas com as comidas da região e, as que se deparam com novos sabores durante o evento. 
A fim de garantir a qualidade dos dados em uma população mais homogênea (20/80) foi determinado um erro amostral de 5\% com a margem de confiança de $95 \%$ e, optou-se pela aplicação de 283 questionários semi-estruturados com participantes da festa, durante o período do evento. Para definição desta quantidade foi utilizada a determinação de amostra aleatória simples, uma vez que a probabilidade de escolha era igual para todos os entrevistados. Para isso, utilizou-se a equação:

$$
n=\frac{N \cdot Z^{2} \cdot p \cdot(1-p)}{Z^{2} \cdot p \cdot(1-p)+e^{2} \cdot(N-1)}
$$

Onde:

$\mathrm{n}=$ amostra

$\mathrm{N}=$ população

$\mathrm{Z}$ = variável normal padronizada associada ao nível de confiança

$\mathrm{p}=$ verdadeira probabilidade do evento

$\mathrm{e}=$ erro amostral.

Para a realização das entrevistas e aplicação dos questionários com comerciantes e frequentadores da festa foram respeitadas as orientações da Resolução MS no 510/2016 (Brasil, 2016), que trata sobre procedimentos éticos para pesquisas envolvendo seres humanos. A autorização para a coleta de dados e sua participação na pesquisa ocorreu pela leitura e assinatura do Termo de Consentimento Livre e Esclarecido, por parte de todos os participantes. A aprovação da pesquisa ocorreu através do Comitê de Ética em Pesquisa com Seres Humanos (CEP) do Hospital Lauro Wanderley da Universidade Federal da Paraíba, sob número de protocolo CEP/HULW no 297/11.

Os dados obtidos foram submetidos ao teste de hipóteses com $5 \%$ de erro, no software SPSS 20.0 (Guimarães, 201-).

\section{Resultados e discussão}

No início das entrevistas com os comerciantes foi indagado qual era a origem dos trabalhadores que utilizam as barracas montadas pela prefeitura, uma vez que os dos estabelecimentos locais são geridos pelos moradores do município. Verificou-se que dos 13 vendedores informais cadastrados pela prefeitura, apenas dois $(15,38 \%)$ eram da região, sendo um de Cabaceiras e o outro do município de Boqueirão. De acordo com Dutra (2004), a prefeitura faz o cadastro com comerciantes locais e das regiões vizinhas, para que os mesmos recebam a concessão pelas barracas. Por esse motivo, a maioria $(84,62 \%)$ dos vendedores cadastrados não só eram de outras regiões da Paraíba, mas pertenciam inclusive a outros estados, como Pernambuco, Rio Grande do Norte e Ceará. Esses dados são relevantes, pois mostram que, apesar de haver movimentação da economia, os moradores do município têm pouco envolvimento e participação no ramo alimentício, para este tipo de atividade temporária. Com isso, perdem oportunidades de geração e/ou aumento de renda na época do evento.

A mesma situação também foi relatada por Neves (2016) no Festival da Lula em Arraial do Cabo (Rio de Janeiro), onde os pescadores não são os responsáveis 
pela parte de confecção alimentar e sim, pelas pessoas que já trabalham e têm experiência no ramo de alimentação em festas populares. Nesse mesmo estudo, os profissionais responsáveis pela captura da matéria prima relataram que 0 investimento financeiro na preparação dos pratos era vantajoso e que preferiam continuar apenas com a comercialização das lulas. Já na festa do Bode Rei, alguns comerciantes locais informaram que um dos motivos que atrapalham a maior participação popular nessa área é o valor do aluguel cobrado pela prefeitura. Segundo os entrevistados, a participação de comerciantes de outros Estados faz com que os preços dos alimentos sejam elevados, uma vez que os mesmos necessitam cobrar valores maiores sobre os produtos para justificar $o$ deslocamento até Cabaceiras.

Apesar da modesta participação direta dos populares no setor alimentício não significa que os mesmos não participem de forma indireta neste setor do evento, uma vez que a festa tem como principal personagem o bode, que é uma das maiores movimentações econômicas da região. A partir dessa perspectiva estimase que foram comercializadas cinco toneladas da carne do animal na edição de 2017 (Globo, 2017), cuja obtenção do mesmo pode ocorrer das mais diversas formas.

Dos 21 estabelecimentos que trabalham com alimentação pronta para consumo, a feira livre é a opção de cinco comerciantes $(23,8 \%)$, enquanto três $(14,3 \%)$ adquirem os alimentos de fornecedores. Outros três $(14,3 \%)$ fazem negócio com os marchantes (profissionais que comercializam carne animal), que foi descrita como a pessoa que abate e separa os diversos cortes do animal. Negociar diretamente com o criador é a escolha de quatro comerciantes (19\%); dois $(9,5 \%)$ informaram que também são criadores de caprino/ovinos e, apenas uma pessoa $(4,8 \%)$ afirmou adquirir o produto em supermercado. Apenas três dos entrevistados $(14,3 \%)$ não informaram onde adquiriam a matéria prima.

A origem dos animais utilizados costuma ser dos criadores da região e o abate também ocorre no local. Em passagem no matadouro municipal de Cabaceiras os trabalhadores informaram que a quantidade de abates realizados no dia que antecede a festa e nos dias correntes aumenta de forma considerável, em mais que o dobro dos dias comuns. Por se tratar de um local público, o mesmo está disponível para o uso de todos, sendo pago apenas a pessoa que abate, limpa e corta o caprino.

Apesar do bode ser o elemento principal nesta festa, uma preparação necessita de outros ingredientes. De acordo com Neves (2016), esses outros comércios paralelos movimentam vários setores da economia da região. Os demais ingredientes utilizados na preparação das comidas consumidas na festa, como verduras e legumes, costumam ser obtidos de produtores locais por 17 comerciantes (81\%). Tais ingredientes podem ser oriundos da região (nativos) ou introduzidos na mesma (exóticos). Apesar de 12 comerciantes indicarem que fazem uso de plantas nativas, percebeu-se que os mesmos não sabiam diferenciálas, pois citavam temperos exóticos à Caatinga como coentro e cebolinha, que são originárias do sul da Europa, norte da África e Mediterrâneo, e Sibéria e Mongólia respectivamente, mas já se encontram na região há longo tempo (Casagrande, 2013). 
Esta mistura de conceitos e origens é muito comum quando uma planta já está sendo utilizada na localidade por várias gerações e, também quando as plantas nativas são substituídas pelas exóticas, fato muito frequente em excolônias (Batista, 2016). A obtenção de boa parte dos produtos utilizados na confecção dos alimentos é do próprio município de Cabaceiras. Apenas um dos comerciantes relatou que, por se morador da cidade vizinha de Boqueirão, é de lá que traz todos os seus insumos.

Baseado em tais informações pode-se perceber que, apesar da comunidade não participar de maneira expressiva na comercialização de alimentos nas barracas montadas em um dos polos da festa, eles se envolvem indiretamente uma vez que os alimentos vendidos durante o evento promovem uma elevação no mercado agropecuário da região, valorizando seus manejos e produções tradicionais.

Além da origem dos ingredientes, a origem das receitas também é de grande importância quando se trata de preparações tradicionais. De acordo com Muchen e Garcia (2015), é a preservação das receitas que atrai o turista para as festas tradicionais, pois o mesmo nota a culinária como reflexo da cultura regional. De acordo com 15 comerciantes $(71,4 \%)$, as receitas utilizadas no festejo são oriundas da própria família, enquanto quatro comerciantes (19\%) afirmaram serem os autores das próprias receitas. Apenas um entrevistado $(4,8 \%)$ recorreu a livros e, a mesma quantidade $(4,8 \%)$ fez uso da internet para tal fim.

Percebe-se assim que as preparações comercializadas na Festa do Bode Rei são, em sua maioria, de origem tradicional. Isso permite que os participantes da festa percebam um pouco do cotidiano alimentar da região. Tal fato também foi relatado por Carvalho (2016) ao estudar a Festa do Divino Espírito Santo, em Alcântara, Maranhão. Nela os turistas e visitantes conhecem o cotidiano local além do estilo de vida e da gastronomia. Porém, em Alcântara, diferente de Cabaceiras, os alimentos e bebidas típicas são comercializados por moradores que aproveitam a ocasião para incrementar a renda familiar.

Todo o alimento adquirido é utilizado para o consumo do público frequentador da festa, que é originário das mais diversas regiões. Dos 283 participantes entrevistados, apenas 55 são moradores de Cabaceiras (19,43\%). A maioria dos frequentadores $(80,57 \%)$ são oriundos de outros municípios e Estados. Esse dado mostra a relevância desta festa que, mesmo distante da capital do Estado, mobiliza grande público. Ao atrair público externo nessa magnitude, a festa popular não só tem a oportunidade de reforçar hábitos e costumes locais, como também divulga a região e sua cultura para outros estados e regiões. Sob o ponto de vista cultural esse dado é importante pois fortalece a cultura do município, estimulando a continuidade do evento em anos subsequentes. De acordo com Guerreiro e Bridi (2015), esse dado é esperado para festas populares onde ocorre uma grande movimentação de participantes. Em relação à origem dos visitantes frequentadores estes foram oriundos das duas maiores cidades paraibanas, João Pessoa e Campina Grande, como pode ser observado na tabela 1.

Tabela 1. Origem dos visitantes participantes da Festa do Bode Rei, edição 2017, Cabaceiras, Paraíba, Brasil. 


\begin{tabular}{|c|c|c|}
\hline Localidade & Quantidade & Porcentagem \\
\hline João Pessoa - PB & 78 & 27,6 \\
\hline Campina Grande - PB & 28 & 9,9 \\
\hline Boqueirão - PB & 12 & 4,2 \\
\hline Queimadas - PB & 10 & 3,5 \\
\hline Cabedelo - PB & 7 & 2,5 \\
\hline Condado - PE & 6 & 2,1 \\
\hline Santa Rita - PB & 6 & 2,1 \\
\hline Araçagi - PB & 5 & 1,8 \\
\hline Pernambuco & 4 & 1,4 \\
\hline Recife - PE & 4 & 1,4 \\
\hline Rio de Janeiro - RJ & 4 & 1,4 \\
\hline Santa Cruz - PE & 4 & 1,4 \\
\hline São Paulo - SP & 4 & 1,4 \\
\hline Caicó - RN & 3 & 1,1 \\
\hline Massaranduba - PB & 3 & 1,1 \\
\hline Olinda - PE & 3 & 1,1 \\
\hline Pirpirituba - PB & 3 & 1,1 \\
\hline Bonito de Santa Fé - PB & 2 & 7 \\
\hline Brasília - DF & 2 &, 7 \\
\hline Goiana - PE & 2 & 7 \\
\hline Lucena - PB & 2 & 7 \\
\hline Mamanguape - PB & 2 & 7 \\
\hline Salgado de São Félix - PB & 2 & ,7 \\
\hline Santo André - PB & 2 &, 7 \\
\hline São Domingos Cariri - PB & 2 &, 7 \\
\hline Boa Vista - PB & 1 & 4 \\
\hline Bom Jardim - PE & 1 &, 4 \\
\hline Caruaru - PE & 1 & 4 \\
\hline Catuité - PB & 1 &, 4 \\
\hline E.U.A. & 1 & ,4 \\
\hline Guarabira - PB & 1 & 4 \\
\hline Mari - PB & 1 & 4 \\
\hline Minas Gerais & 1 &, 4 \\
\hline Mossoró - RN & 1 &, 4 \\
\hline Natal - RN & 1 & ,4 \\
\hline Paudalho - PE & 1 & 4 \\
\hline Pombal - PB & 1 & 4 \\
\hline Porto Seguro - BA & 1 & 4 \\
\hline Ribeirão - PB & 1 & ,4 \\
\hline São João do Cariri - PB & 1 & ,4 \\
\hline Sapé - PB & 1 & 4 \\
\hline Taquaritinga do Norte - PE & 1 & 4 \\
\hline Não informaram & 11 & 3,9 \\
\hline Total & 228 & 80,6 \\
\hline
\end{tabular}

Observou-se que 78 entrevistados $(27,56 \%)$ eram oriundos da capital João Pessoa e, apenas 28 (9,89\%) eram de Campina Grande, que é uma cidade importante para o estado da Paraíba e fica mais próxima do festejo do que a capital. Em relação à frequência de visita à Festa do Bode Rei, mais da metade dos entrevistados $(54,41 \%$ ou 154 pessoas) afirmaram não ser a primeira vez que 
visitavam o evento. Destes, 103 afirmaram não residir no município sede da festa. Esse elevado índice de retorno pode ser um dos responsáveis pelo aumento da expectativa de público do evento ter aumentado em 20\% dos 50 mil em 2016 (Duarte, 2016) para 60 mil em 2017 (Costa, 2017). Tal variação ocorre em praticamente todas as festas, pois a cada edição as mesmas ficam mais conhecidas e popularizadas (Silva et al., 2014). Esse fato pode ser responsável pela continuidade da mesma, permitindo que os moradores tenham uma maior segurança de continuidade e de perpetuação dos seus costumes.

$\mathrm{Na}$ análise estatística da comparação do índice de retorno entre os moradores e os turistas, o resultado apresentou-se significativo ( $p<0,05$ ), indicando que os moradores de Cabaceiras e cidades vizinhas frequentam mais a festa do que os turistas, com diferenças estatisticamente significativas entre os dois grupos. Tal fato ocorre devido aos moradores não precisarem de grande esforço de deslocamento e hospedagem para participação da festa. Durante a pesquisa foi percebido que o Município de Cabaceiras é carente de uma rede hoteleira capaz de absorver o impacto da festa e os visitantes. Este fato pode dificultar a presença de turistas de regiões mais distantes, os quais necessitam de oferecimento de vagas e hotéis para repouso e descanso.

Quando questionados sobre a principal motivação para frequentar a festa, o lazer foi o item mais citado, sendo a opção de 146 entrevistados (51,59\%). Destes, 46 ainda afirmaram que só retornam à festa anualmente por motivos de lazer. 0 lazer e descanso, também foram observados por Neves (2016) como principais motivações do turista para participação no Festival da Lula, em Arraial do Cabo, estado do Rio de Janeiro. Ainda nesse evento, foi observada a presença de turistas chamados "gourmets". Esses buscavam o alimento como principal atrativo no evento, embora a lula não seja considerada um item da gastronomia local.

A alimentação propriamente dita foi a terceira motivação de participação, citada por 51 entrevistados (18\%). A segunda motivação para participação na festa foram os negócios, citados por 60 entrevistados (21,2\%). Ao dividir os participantes em moradores e turistas, tem-se os negócios como principal motivação de participação para o primeiro grupo com 26 moradores (43,63\%), seguido do lazer para 18 moradores (19,78\%). No entanto, no segundo grupo o lazer é a principal motivação de participação, revelado por 131 turistas (57,45\%), seguida da alimentação, citada por 44 turistas (19,29\%).

Ao analisar estatisticamente os dois públicos, a respeito da comida ser uma motivação de participação das festas, observa-se que o resultado foi significativo $(\mathrm{p}<0,05)$, indicando que moradores frequentam mais a festa devido à comida do que os turistas. Já em relação à comida sendo um motivo de retorno, o resultado não foi significativo $(\mathrm{p}>0,05)$, indicando que não há diferenças entre os moradores e os turistas no que diz respeito à vontade de retornar à festa para comer bode e seus derivados. Porém, de acordo com Munchen e Garcia (2015), para o turista que procura lazer, a gastronomia típica é um dos fatores de relevância como atrativo. A partir deste conceito pode-se perceber que a alimentação passa a ser uma das principais motivações de participação e retorno, pois a mesma faz parte do conceito de entretenimento e lazer.

Todo esse público que busca eventos festivos em algum momento irá alimentar-se e as opções oferecidas eram os restaurantes/lanchonetes locais ou as 
barracas montadas nas calçadas e ruas do local do festejo. Quando se tratava de preferências em relação ao tipo de estabelecimento para consumo alimentar, 127 entrevistados (44,87\%) disseram alimentar-se em barracas, 105 (37,10\%) optavam pelas lanchonetes e restaurantes, 45 pessoas $(15,90 \%)$ afirmaram não se alimentar no local e apenas seis entrevistados (2,13\%) não fazia distinção na escolha entre os dois tipos de local para alimentação (Figura 1).

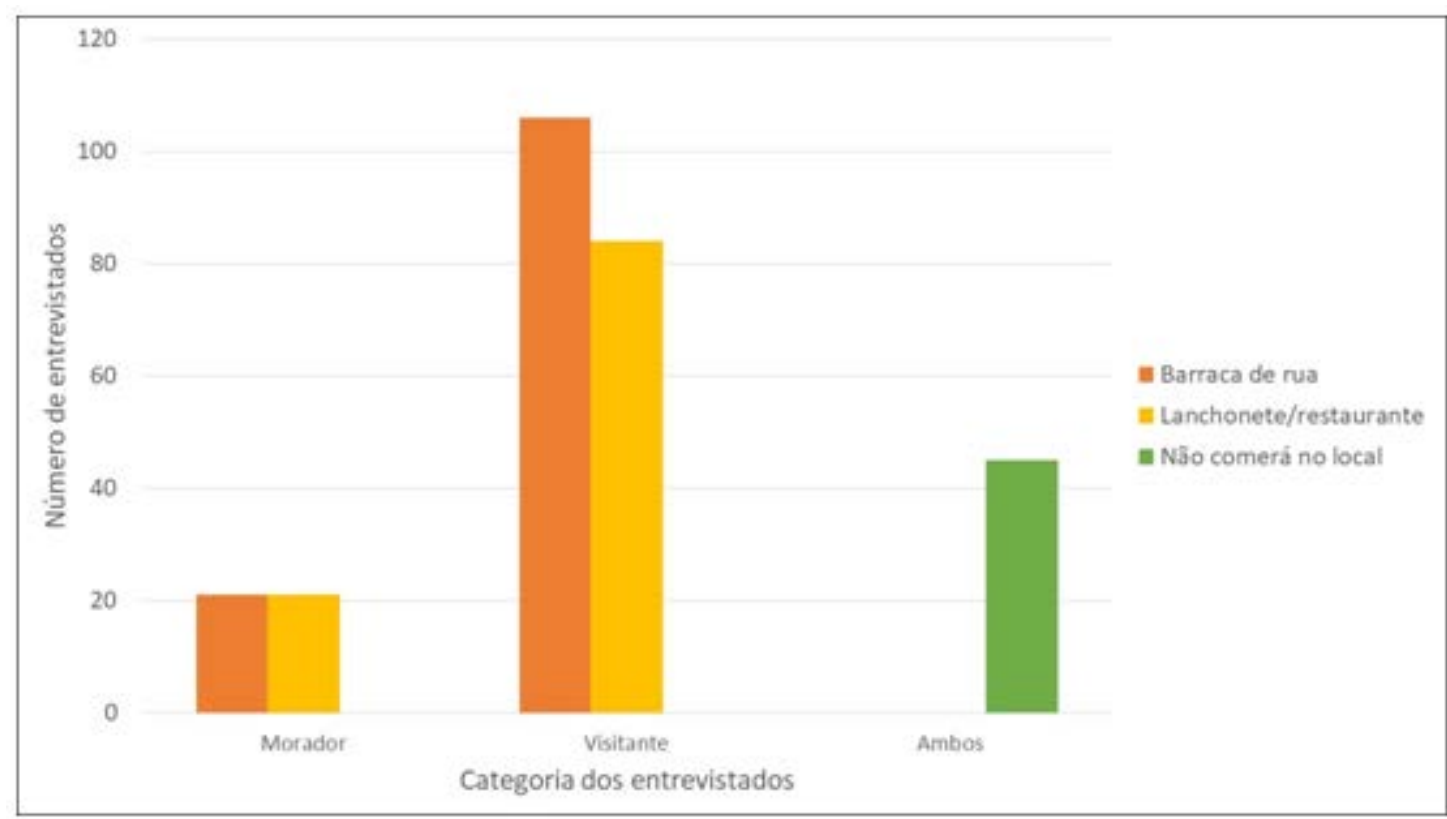

Figura 1. Preferência dos visitantes da festa entrevistados em relação ao tipo de estabelecimento que comercializa alimentos na Festa do Bode Rei, edição 2017. Cabaceiras, Paraíba, Brasil.

Ao realizar a análise estatística verificou-se que a diferença da média da escolha dos dois grupos não foi significativa $(\mathrm{p}>0,05)$, indicando que não existe diferença de preferências entre moradores e os turistas no que diz respeito a preferir barracas ou lanchonetes. Isso faz com que ambas as modalidades de estabelecimento atendam a todos os públicos. Nos trabalhos de Carvalho (2016) e Neves (2016) não houve distinção entre os estabelecimentos que os participantes da festa iriam se alimentar, em ambos os trabalhos os autores falam apenas das barracas montadas na rua para os eventos.

Para atender toda a demanda culinária da festa, os comerciantes necessitam de quantidades elevadas de alimentos e insumos. A maioria dos comerciantes, independentemente do tipo de estabelecimento que comercializa alimentos, relatou que a carne de bode é o principal atrativo para a culinária no evento. Este dado comprova que o caprino e seus produtos derivados possuem lugar de destaque no evento. A presença do caprino e seus derivados fortalece a tradição e os costumes daquela sociedade e, consequentemente, a soberania alimentar da região. Esta afirmação confirma-se pelos dados que podem ser vistos na Figura 2. Porém, nem sempre esse respeito às tradições locais é mantido em grandes eventos. Na Oktoberfest, realizada anualmente em Blumenau, em Santa Catarina, algumas das suas edições apresentou uma maior ênfase em outras atrações do que as ligadas à cultura alemã, conforme relatado por Silva et al. (2014). 

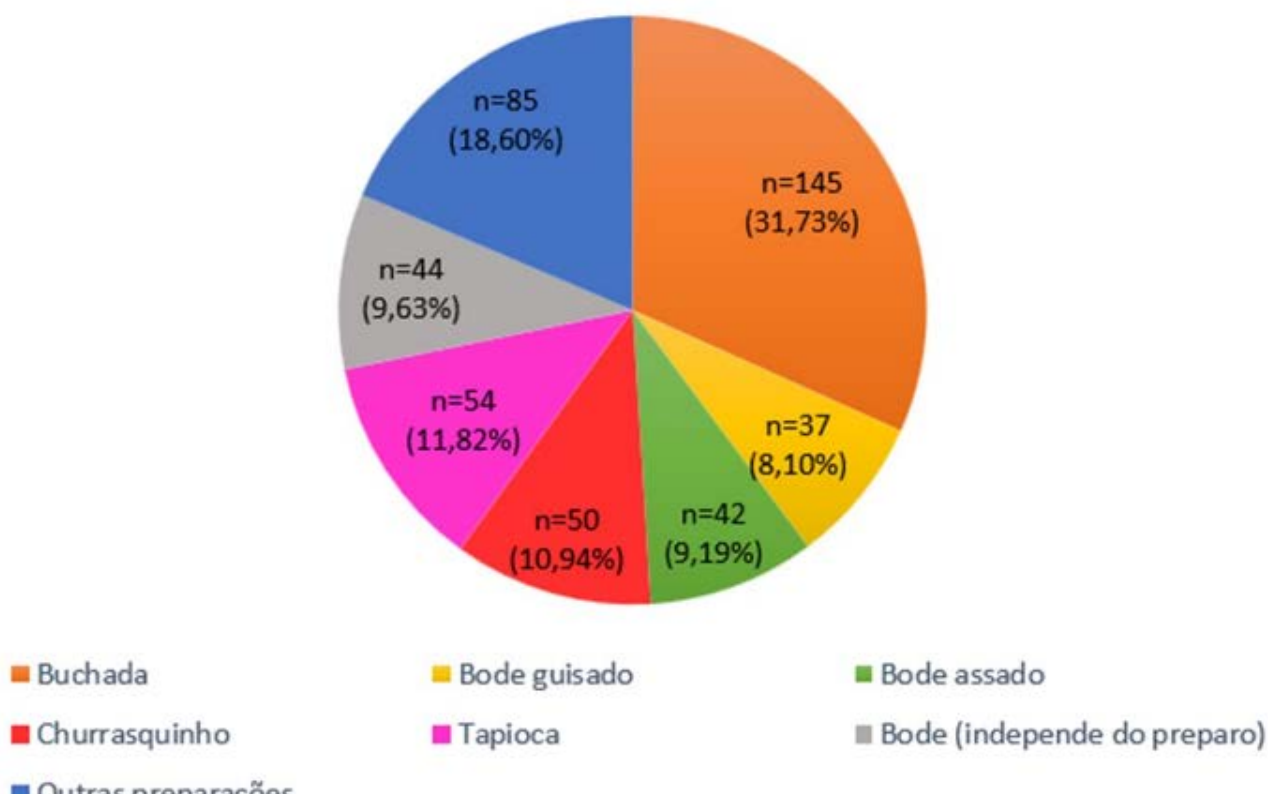

Figura 2. Intenção de consumo de preparos culinários pelos visitantes na Festa do Bode Rei, edição 2017, Cabaceiras, Paraíba, Brasil.

Os dados apresentados da Figura 2 revelam que 58,65\% dos entrevistados afirmaram que iriam consumir algum tipo de preparo culinário em que a carne de bode estivesse presente. Estes valores reforçam ainda mais a soberania alimentar de região e comprovam que o bode, principal atrativo e que dá nome à festa, é fortemente apreciado pelos frequentadores. Essa elevada procura pelo bode não se dá apenas porque a festa tem o mesmo como principal personagem, pois $78,1 \%$ dos entrevistados $(n=221)$ informaram que gostam muito ou gostam da carne do bode, 3,5\% $(\mathrm{n}=10)$ afirmaram que não gostam, $8,5 \%$ detestam $(n=24)$ e 9,2\% ( $n=29)$ são indiferentes ao sabor do caprino.

Apesar de haver respeito às tradições culinárias e os preparos culinários terem um valor elevado para as barracas, constatou-se que as mesmas são apresentadas de forma muito rústica, abrindo uma lacuna à confecção de pratos com apresentações mais elaboradas. Faz-se necessário que haja um equilíbrio entre a apresentação estética da barraca e o preparo culinário que é servido, para que o turista ou morador visitante da festa possa se sentir atraído e dar o devido valor à comida que é comercializada no festejo.

Ao realizar um comparativo estatístico pela diferença de médias entre os moradores e os turistas em relação à apreciação da carne de caprino, o resultado foi significativo $(\mathrm{p}<0,05)$, indicando que moradores apreciam mais a carne de bode do que os turistas. Essa diferença pode ser decorrente da cultura alimentar da região, uma vez que o caprino faz parte da cultura alimentar da comunidade, sendo ofertada desde cedo para consumo, havendo uma naturalidade em seu consumo na região.

Apesar da preferência dos moradores a respeito da apreciação de sabor, não foram percebidas diferenças de frequência de consumo de carne de bode entre os dois públicos, uma vez que o resultado não foi significativo $(p>0,05)$. A partir dessa informação pode-se constatar que as pessoas que frequentam a Festa do Bode Rei são consumidoras habituais do bode e seus derivados, podendo este fato ser também uma das motivações indiretas de participação do evento. 
A partir dessa perspectiva foi indagado aos participantes se os mesmos estariam dispostos a provar novas preparações à base do animal. Verificou-se que $83,7 \%$ dos entrevistados informaram que estariam abertos a novos sabores da carne caprina. Ao dividir o grupo de entrevistados para análise estatística, o resultado não foi significativo ( $\mathrm{p}$ $>0,05)$, indicando que não há diferenças entre os moradores de Cabaceiras e cidades vizinhas e os turistas no que diz respeito à disposição para comer se houvesse mais pratos à base de carne de bode na festa. Tal fato pode ocorrer porque ambos os públicos apreciam e consomem o animal frequentemente.

\section{Conclusão}

A Festa do Bode Rei reflete a cultura do bode no Município de Cabaceiras. Concluiu-se que os turistas são a maior parte de participantes da mesma e o lazer/entretenimento oferecido por essa festa é a principal motivação para participação e retorno das pessoas.

A culinária típica da região do semiárido nordestino é encontrada no evento, promovendo uma disseminação cultural. Como praticamente tudo que é consumido na festa é oriundo da região, pode-se dizer que a festa movimenta muitos setores e não somente o de criação de caprino. Porém as espécies nativas não costumam ser utilizadas e costumam ser confundidas com as exóticas, que já são produzidas por um longo período na região.

A maior parte das pessoas que participa da festa do Bode Rei não são do município de Cabaceiras, apesar da população local ter uma maior taxa de retorno. De um modo geral, os participantes preferem as barracas montadas na rua do que estabelecimentos fixos. Porém, ao analisar os dois grupos de frequentadores (turistas e moradores da região), não há diferença estatística entre eles. Da mesma forma, não existe diferença na frequência de consumo do animal no cotidiano dos dois grupos, apesar dos moradores apreciarem mais o caprino do que os visitantes.

Conclui-se que a Festa do Bode Rei cumpre seu papel de auxiliar no desenvolvimento do município de Cabaceiras, proporcionando movimentação da economia, geração de emprego temporário e renda, além de ser um modo de resistência e transmissão da cultura da região.

\section{Conflito de interesses}

Os autores declaram não haver conflito de interesses.

\section{Referências}

Aluko, O. O.; Ojeremi, T. T.; Olaleke, D. A.; Ajidagba, E. B. Evaluation of food safetyand sanitary practices among food vendors at car parks in Ile Ife, Southwestern Nigeria. Food Control, v. 40, p. 165-171, 2014. https://doi.org/10.1016/j.foodcont.2013.11.049

Alves, J. J. A.; Souza, E. N. D.; Araújo, M. A. D. Estudo descritivo da tipologia turística do Município de Cabaceiras - Paraíba. Caderno Virtual de Turismo, v. 8, n. 3, p. 86-103, 2008.

Aquino, R. S.; Lemos, C. G.; Alencar, C. A.; Silva, E. G.; Lima, R. S.; Gomes, J. A. F.; Silva, A. F. A realidade da caprinocultura e ovinocultural no semiárido brasileiro: um retrato do Sertão do Araripe, Pernambuco. Publicação em Medicina Veterinária e Zootecnica, v. 10, n. 4, p. 271-281, 2016. https://doi.org/10.22256/pubvet. v10n4.271-281 
Batista, M. D. S. Espécies vegetais nativas da flora do Brasil utilizadas na alimentação da região Nordeste: diversificando a dieta e a produção agrícola. Brasília: Universidade de Brasília, 2016.

Batista, N. L.; Souza, B. B. D. Caprinovinocultura no semiárido brasileiro: fatores limitantes e ações de mitigação. Agropecuária Científica no Semiárido, v. 11, n. 2, p. 1-9, 2015.

Biernacki, P.; Waldorf, D. Snowball sampling: Problems and techniques of chain referral sampling. Sociological Methods \& Research, v. 10, p. 141-163, 1981. https://doi.org/ $10.1177 / 004912418101000205$

Brasil. Resolução CNS no 510, de 7 de abril de 2016. Disponível em: <http://bvsms. saude.gov.br/bvs/saudelegis/cns/2016/res0510_07_04_2016.html>. Acesso em: 23 set. 2019.

Brito, L. M. P.; Santos, M. E. D. L.; Gurgel, F. F. Desenvolvimento local e "O Maior São João do Mundo". Anais do Encontro de Administração Pública e Governo, Salvador, 2012.

Campos, R. F. F.; Ferreira, J. F.; Mangueira, M. N.; Gonçalves, M. C. R. Gastronomia nordestina: na mistura de sabores brasileiros. Anais do XI Encontro de Iniciação à Docência, 2009.

Caponero, M.C.; Leite, E. Inter-relações entre festas populares, políticas públicas, patrimônio imaterial e turismo. Patrimônio: Lazer \& Turismo, v. 7, n. 10, p. 99-113, 2010.

Carvalho, K. D. Análise do potencial turístico da Festa do Divino Espírito Santo em Alcântara, Maranhão, Brasil. Turismo \& Sociedade, v. 9, p. 1-18, 2016. https://doi.org/ 10.5380/tes.v9i1.45975

Casagrande, V. (Ed.). Manual Natureza ervas e temperos. São Paulo: Europa, 2013.

Cortese, R. D. M.; Veiros, M. B.; Feldman, C.; Cavalli, S. B. Food safety and hygiene practices of vendors during the chain of street food production in Florianopolis, Brazil: A crosssectional study. Food Control, v. 62, p. 178-186, 2016. https://doi.org/10.1016/ j.foodcont.2015.10.027

Costa, R. G.; Almeida, C. C.; Pimenta Filho, E. C.; Holanda Junior, E. V.; Santos, N. M. Caracterização do sistema de produção caprino e ovino na Região Semi-Árida do Estado da Paraíba. Archivos de Zootecnia, v. 57, n. 218, p. 195-205, 2008.

Costa, V. Festa do Bode Rei movimenta economia de Cabaceiras. Agência Sebrae de Notícia, 04 jun. 2017. Disponível em: <http://www.pb.agenciasebrae.com.br/sites/asn/uf/PB/ festa-do-bode-rei-movimenta-economia-de-cabaceiras,cae5339e70a6c510VgnVCM 1000004c00210aRCRD>. Acesso em: 21 jun. 2017.

Duarte, T. A Terra em que o Bode é Rei. A União, p. 24, 21 maio 2016.

Globo. Festa do Bode Rei, na PB, estima vender quase cinco toneladas de carne em três dias, 2017. Disponível em: <http://g1.globo.com/pb/paraiba/sao-joao/2017/ noticia/festa-do-bode-rei-na-pb-estima-vender-quase-cinco-toneladas-de-carne-em-tresdias.ghtml>. Acesso em: 21 jun. 2019.

Godoi, E. D. S. A produção da identidade paraibana na propaganda da cullinária nordestina. João Pessoa: Universidade Federal da Paraíba, 2008.

Guerreiro, B.; Bridi, G. Eventos gastronômicos como vetores para o desenvolvimento turístico. Um estudo de caso da Fenadoce Pelotas-RS. Fólio - Revista Científica Digital Jornalismo, Publicidade e Turismo, n. 1, p. 17-35, 2015. https://doi.org/10.15602/ 1981-3422/folio.n1p17-35 
Guimarães, J.-B. D. S. Análise estatística utilizando o SPSS: guia prático de comandos. Salvador: [s.n.], 201-. (Apostila). Disponível em: <https://social.stoa.usp.br/articles/0016/ 4636/Apostila-SPSS.pdf>. Acesso em: 30 out. 2019.

Lakatos, E. M.; Marconi, M. A. Fundamentos de metodologia científica. 4. ed. São Paulo: Atlas, 2002.

Lóssio, R. A. R.; Pereira, C. M. A Importância da valorização da cultura popular para o desenvolvimento local. Anais do III Encontro de Estudos Multidisciplinares em Cultura, Salvador, Faculdade de Comunicação, UFBA, 2007.

Martins, S. A experiência da modernidade e o patrimônio cultural. Revista de Estudos e Investigações Antropológicas, v. 1, n. 1, p. 7-29, 2014.

Mendes, M. D. C.; Pires, P. D. S. D. S.; Krause, R. W. Relevância da gastronomia em restaurantes temáticos: um estudo de caso em Balneário Camboriú, SC. Rosa dos Ventos: Turismo e Hospitalidade, v. 6, n. 1, p. 66-75, 2014.

Munchen, J.; Garcia, R. K. O. 0 interesse dos viajantes pelos elementos gastronômicos do turismo. Revista Conhecimento Online, v. 1, p. 94-103, 2015.

Neves, A. A. D. Uma reflexão sobre a importância de um festival gastronômico como recurso turístico: um estudo do festival da lula em Arraial do Cabo (RJ). Caderno de Gestão e Empreendedorismo, v. 4, n. 3, p. 58-70, 2016. https://doi.org/10.32888/ cge.v4i3.12699

Nunes, O. L. D. S. B.; Santos Junior, E. R.; Rosas, R. C. P.; Chaves, R. M.; Barros, G. F. N. P.; Torres, P. B.; Coelho, E. R. Uso do efeito macho associado a diferentes durações de estação de monta em caprinos no semiárido pernambucano. Acta Scientiae Veterinariae, v. 42, Pub. 1232, 2014.

Okojie, P. W.; Isah, E. C. Sanitary conditions of food vending sites and food handling practices of street food vendors in Benin City, Nigeria: Implication for food hygiene and safety. Journal of Environmental and Public Health, Article ID 701316, 6 pag., 2014. https://doi.org/10.1155/2014/701316

Papes, A. C.; Sousa, J. M. D. Cabaceiras: a cidade turística no Cariri da Paraíba. Informe Gepec, v. 15, n. 2, p. 118-133, 2011.

Pereira, R. A. A integração das várias formas de turismo como fator para o desenvolvimento para os Cariris Velhos. Anais do IX Encontro Latino-Americano de Iniciação Científica e V Encontro Latino-Americano de Pós-Graduação, Universidade do Vale do Paraíba, p. 11615-1618, 2006.

Pereira, R. R.; Souza, A. D. O. 0 discurso da estiagem como fator limitante ao crescimento econômico: um estudo de caso na Cidade de Cabaceiras-PB. Revista Geonorte, v. 4, n. 12, p. 503-519, 2013.

Pinheiro, A. Cabra da Peste: Cabaceiras, na Paraíba, coroa bode em festa popular. Folha de S. Paulo, 29 maio 2003. Disponível em: <http://www1.folha.uol.com.br/fsp/ turismo/inde19052003.htm>. Acesso em: 24 jan. 2017.

Qureshi, S.; Vaida, N.; Azim, H. Hygiene practices and food safety knowledge among street food vendors in Kashmir. International Journal of Scientific Research, v. 4, n. 8, p. 723-726, 2015.

Reis, M. Infância e cultura. Pedagogia em Ação, v. 3, n. 1, p. 5-14, 2013. 
Ribeiro, E. M. S.; Arroyo-Rodríguez, V.; Santos, B. A.; Tabarelli, M.; Leal, I. R. Chronic anthropogenic disturbance drives the biological impoverishment of the Brazilian Caatinga vegetation. Journal of Applied Ecology, v. 52, p.611-620, 2015. https://doi.org/ 10.1111/1365-2664.12420

Rodrigues, B. F.; Góes, J. A. W.; Cardoso, R. C. V.; Souza, W. M.; Ferreira, T. C. B. 0 comércio de comida de rua no Centro Histórico de Salvador-BA: caracterização da oferta de alimentos e aspectos higiênico-sanitários. Segurança Alimentar e Nutricional, v. 21, n. 1, p. 347-358, 2014. https://doi.org/10.20396/san.v21i1.8638932

Silva, L. F. D.; Mantovaneli Júnior, O.; Sampaio, C. A. C. Desenvolvimento turístico regional: Governança e territorialidade no caso da Oktoberfest Blumenau (Santa Catarina, Brasil). Turismo \& Sociedade, v. 7, n. 1, p. 156-173, 2014. http://dx.doi.org/10.5380/ tes.v7i1.37147

Silva, S. A. D.; Cardoso, R. C. V.; Góes, J. A. W.; Santos, J. N.; Ramos, F. P.; Jesus, R. B.; Vale, R. S.; Silva, P. S. T. Street food on the coast of Salvador, Bahia, Brazil: A study from the socioeconomic and food safety perspectives. Food Control, v. 40, p. 78-84, 2014. https://doi.org/10.1016/j.foodcont.2013.11.022

Silva, S. D.; Medeiros, V. P.; Silva, A. B. Tecnologias sociais hídricas para convivência com o semiárido: 0 caso do assentamento rural do Município de Cabaceiras-PB. Holos, v. 1, p. 295-309, 2016. https://doi.org/10.15628/holos.2016.3312

Informação da Licença: Este é um artigo Open Access distribuído sob os termos da Licença Creative Commons Attribution, que permite uso irrestrito, distribuição e reprodução em qualquer meio, desde que a obra original seja devidamente citada. 